\title{
Primary Care Provider Attitudes and Practices Evaluating and Managing Patients with Neurocognitive Disorders
}

\author{
Alissa Bernstein, PhD, MPH ${ }^{1,2}$, Kirsten M. Rogers, BA ${ }^{3}$, Katherine L. Possin, PhD ${ }^{3}$, \\ Natasha Z. R. Steele, MPH $H^{3,4}$, Christine S. Ritchie, MD, MSPH ${ }^{5}$, Bruce L. Miller, MD ${ }^{2,3}$, and \\ Katherine P. Rankin, $P h D^{3}$
}

'Philip R. Lee Institute for Health Policy Studies, University of California, San Francisco, San Francisco, CA, USA; ${ }^{2}$ Global Brain Health Institute, University of California, San Francisco, San Francisco, CA, USA; ${ }^{3}$ Memory and Aging Center, Department of Neurology, University of California, San Francisco, San Francisco, CA, USA; ${ }^{4}$ University of Washington School of Medicine, Seattle, WA, USA; ${ }^{5}$ Division of Geriatrics, Department of Medicine, University of California, San Francisco, San Francisco, CA, USA.

J Gen Intern Med 34(9):1691-2

DOI: $10.1007 / \mathrm{s} 11606-019-05013-7$

(c) Society of General Internal Medicine 2019

\section{INTRODUCTION}

The prevalence of dementia, a neurocognitive disorder (NCD), is expected to triple in the next 30 years. Accurate diagnosis of NCDs determines prognosis, anticipatory guidance, and symptomatic treatment, and is necessary to identify cases with reversible underlying conditions. ${ }^{1}$ Primary care providers (PCPs) are typically the first to recognize that a patient may have a NCD (including mild cognitive impairment or dementia). However, PCPs frequently do not evaluate further, and when they do, they often refer to specialists rather than testing and diagnosing within their practice. Both PCPs and patients commonly report trouble accessing specialists, and more than half of patients do not follow through with referrals. ${ }^{2,3}$ While PCPs have identified systems-level barriers to the assessment of their patients with NCDs, including lack of resources and inadequate time to educate patients and families after a diagnosis of dementia, data on actual PCP attitudes and evaluation and management practices are sparse. ${ }^{4}$ Understanding PCP practices and practice barriers may guide efforts to support their evaluation and management of these patients. We surveyed a national sample of PCPs to characterize their attitudes and practices with respect to the evaluation and management of NCDs.

\section{METHODS}

We surveyed the first $100 \mathrm{PCP}$ respondents who met eligibility criteria from a proprietary database of 5 million panelists. Respondents were eligible if they identified as primary care practitioners and evaluated more than 10 patients over age 55 per month. The cross-sectional survey measured clinical practice characteristics (Table 1) and confidence, attitudes, and behaviors related to the diagnosis and management of NCDs. Providers' demographic data and outcome measures were summarized using descriptive statistics.

\section{RESULTS}

Sixty-four percent of PCPs reported high confidence in the general medical care of patients with neurocognitive complaints, but only $23 \%$ were highly confident in providing a prognosis and stage appropriate care for patients with NCDs (Table 2). When PCPs suspect a NCD, 54\% referred their patients to a specialist for a full neurocognitive workup (cognitive assessment, neuroimaging, labs) and 35\% referred patients for comprehensive neuropsychological evaluation, for at least $75 \%$ of their patients. Thirty-five percent implemented standardized cognitive screens in at least $75 \%$ of their patients. Only $20 \%$ of PCPs reported high confidence in their ability to interpret cognitive testing results. Twenty-four percent reported discomfort interpreting MRI results. Only $21 \%$ of PCPs were highly confident that they correctly recognized when a patient had a NCD, while $13 \%$ were highly confident in making a specific diagnosis. A quarter of PCPs identified lack

Table 1 Characteristics of 100 Primary Care Providers' Practices

\begin{tabular}{ll}
\hline \hline Variable & Value \\
\hline Practice setting: $n / 109 *(\%)$ & \\
Academic & $15(13.8)$ \\
Accountable care organization/HMO & $9(8.3)$ \\
Community health center/federally qualified health center & $15(13.8)$ \\
Private practice/private group practice & $64(58.7)$ \\
Other & $6(5.5)$ \\
Self-described medical specialty: $n / 100(\%)$ & $41(20.5)$ \\
Family medicine & $5(2.5)$ \\
General medicine & $44(22.0)$ \\
Internal medicine & $10(5.0)$ \\
Primary care & 18.9 \\
Mean years in practice, post residency $m$ (SD) & $(10.4)$ \\
& \\
Types of formal training in NCD care: $n$ (\%) & $70(52.2)$ \\
CME credits & $28(20.9)$ \\
Professional education through community groups (e.g., & \\
Alzheimer's Association) & $10(7.5)$ \\
Fellowship & $3(2.2)$ \\
Other & $23(17.2)$ \\
Never received any formal training in this area & \\
Estimated no. of patient providers currently manage with & 27.6 \\
Mild cognitive impairment (SD) & $(27.8)$ \\
Dementia (SD) & 23.1 \\
& $(26.4)$ \\
\hline
\end{tabular}

*Providers could identify multiple practice characteristics 
Table 2 Primary Care Providers' Attitudes and Behaviors

\begin{tabular}{|c|c|}
\hline \multirow[t]{2}{*}{ Variable } & \multirow{2}{*}{$\begin{array}{l}\begin{array}{l}\text { PCPs } \\
(n=100)\end{array} \\
\%\end{array}$} \\
\hline & \\
\hline \multicolumn{2}{|l|}{ Medical care and management } \\
\hline $\begin{array}{l}\text { Highly confident in managing the general } \\
\text { medical care of patients with cognitive complaints }\end{array}$ & 64 \\
\hline $\begin{array}{l}\text { Highly confident in providing a prognosis and } \\
\text { stage appropriate care for patients with NCDs. }\end{array}$ & 23 \\
\hline \multicolumn{2}{|l|}{ General referrals } \\
\hline $\begin{array}{l}\text { Referred more than } 75 \% \text { of patients with } \\
\text { suspected NCDs to a neurologist or other specialist } \\
\text { for a full dementia evaluation }\end{array}$ & 54 \\
\hline $\begin{array}{l}\text { Referred more than } 75 \% \text { of patients with suspected } \\
\text { NCDs to a specialist for neuropsychological testing }\end{array}$ & 35 \\
\hline \multicolumn{2}{|l|}{ Cognitive screening and neuropsychological testing } \\
\hline $\begin{array}{l}\text { Performed cognitive screening in more than } 75 \% \\
\text { of their patients with suspected NCDs }\end{array}$ & 35 \\
\hline $\begin{array}{l}\text { Highly confident in interpreting cognitive } \\
\text { test results }\end{array}$ & 20 \\
\hline \multicolumn{2}{|l|}{ Imaging } \\
\hline $\begin{array}{l}\text { Lack familiarity or have discomfort } \\
\text { interpreting MRI results }\end{array}$ & 23.5 \\
\hline \multicolumn{2}{|l|}{ Diagnosis } \\
\hline $\begin{array}{l}\text { Highly confident in correctly recognizing when } \\
\text { a patient has an NCD }\end{array}$ & 21 \\
\hline $\begin{array}{l}\text { Highly confident in making a specific NCD } \\
\text { diagnosis }\end{array}$ & 13 \\
\hline $\begin{array}{l}\text { Identify lack of familiarity with diagnostic criteria } \\
\text { for NCD syndromes as a strong barrier in their } \\
\text { clinical practice }\end{array}$ & 26 \\
\hline \multicolumn{2}{|l|}{ Practice competency } \\
\hline $\begin{array}{l}\text { Moderately to extremely likely to treat more } \\
\text { patients with NCDs rather than referring them } \\
\text { to specialists if decision support tools were available. }\end{array}$ & 76 \\
\hline
\end{tabular}

of familiarity with diagnostic criteria for NCDs as a barrier in their clinical practice. Seventy percent of PCPs reported that they would be moderately to extremely likely to treat more patients with NCDs rather than referring to specialists if decision support tools were available.

\section{DISCUSSION}

While PCPs carry the principal burden of assessing and caring for the majority of patients with NCDs, there is often a significant delay between symptom onset and diagnosis. ${ }^{1,4,5}$ Furthermore, continuity of care for patients with NCDs is a major problem that can lead to delayed diagnosis and impede clinical care and advanced care planning decisions. ${ }^{1}$ Our findings offer a starting point to address this problem by identifying practice barriers that PCPs face, aside from commonly reported systems-level issues such as time and reimbursement. ${ }^{4}$

Our study suggests that PCPs lack confidence in their ability to engage in key aspects of the neurocognitive evaluation, including implementation of screening, interpretation of standard diagnostic procedures, and ability to provide prognosis and stage appropriate care. Specific practice barriers PCPs identified included implementing and interpreting cognitive tests and neuroimaging, and familiarity with diagnostic criteria. Multiple consensus guidelines recommend cognitive testing and neuroimaging as essential aspects of all NCD evaluations to rule out reversible causes of impairment or to make an accurate diagnosis. ${ }^{6}$ New approaches, such as streamlined tools and training, are being designed to support dementia assessment and management in primary care. These tools may help PCPs contextualize diagnostic test results and reduce referrals, ensuring greater continuity of care. In our study, most (70\%) PCPs reported that if they had tools and education, they would be more likely to do neurocognitive assessments. Effective interventions can be achieved given that PCPs are generally eager to improve their decision processes around the identification, diagnosis, and care of their patients with NCDs.

Acknowledgments: Survey administration was carried out by Health Research \& Analytics, a consultative healthcare market research firm based in Parsipanny, NJ.

Corresponding Author: Alissa Bernstein, PhD, MPH; Philip R. Lee Institute for Health Policy Studies University of California, San Francisco, San Francisco, CA, USA (e-mail: alissa.bernstein@ucsf. edu).

Funding Information Funding for the work represented in this manuscript was provided by Quest Diagnostics.

\section{Compliance with Ethical Standards:}

Conflict of Interest: KLP and KPR received project funding from Quest Diagnostics for our project and associated IP. CSR receives royalties from McGraw Hill and UptoDate. BLM receives royalties from Cambridge University Press, Guilford Publications, Inc., Oxford University Press, Neurocase, and Elsevier, Inc. All other authors declare no conflicts of interest.

\section{REFERENCES}

1. Bradford A, Kunik ME, Schulz P, Williams SP, Singh H. Missed and delayed diagnosis of dementia in primary care: prevalence and contributing factors. Alzheimer Dis Assoc Disord. 2009;23(4):306-314. https://doi. org/10.1097/WAD.0b013e318la6bebc.

2. Hinton L, Franz CE, Reddy G, Flores Y, Kravitz RL, Barker JC. Practice constraints, behavioral problems, and dementia care: primary care physicians' perspectives. J Gen Intern Med. 2007;22(11):1487-1492.

3. Boustani M, Perkins AJ, Fox C, et al. Who refuses the diagnostic assessment for dementia in primary care? Int J Geriatr Psychiatry. 2006;21(6):556-563. https://doi.org/10.1002/gps.1524.

4. Boustani $\mathbf{M}$, Callahan $\mathbf{C M}$, Unverzagt $\mathbf{F W}$, et al. Implementing a Screening and Diagnosis Program for Dementia in Primary Care. J Gen Intern Med. 2005;20(7):572-577. https://doi.org/10.1111/J.1525-1497. 2005.0126.X.

5. Shinagawa S, Catindig JA, Block NR, Miller BL, Rankin KP. When a Little Knowledge Can Be Dangerous: False-Positive Diagnosis of Behavioral Variant Frontotemporal Dementia among Community Clinicians. Dement Geriatr Cogn Disord. 2016;41(1-2):99-108. https://doi.org/10.1159/ 000438454

6. McKhann GM, Knopman DS, Chertkow H, et al. The diagnosis of dementia due to Alzheimer's disease: Recommendations from the National Institute on Aging-Alzheimer's Association workgroups on diagnostic guidelines for Alzheimer's disease. Alzheimers Dement. 2011;7(3):263269.

Publisher's Note Springer Nature remains neutral with regard to jurisdictional claims in published maps and institutional affiliations. 